\title{
Long-term recording from the chorda tympani nerve in rats
}

\author{
Yuichi Shimatani ${ }^{\mathrm{a}}$, Svetlana Grabauskiene ${ }^{\mathrm{a}}$, Robert M. Bradley ${ }^{\mathrm{a}, \mathrm{b}, *}$ \\ ${ }^{a}$ Department of Biologic and Materials Sciences, School of Dentistry, University of Michigan, Ann Arbor, MI 48109-1078, USA \\ ${ }^{\mathrm{b}}$ Department of Physiology, Medical School, University of Michigan, Ann Arbor, MI 48109-0622, USA
}

Received 7 January 2002; received in revised form 13 February 2002; accepted 25 February 2002

\begin{abstract}
Cuff electrodes with headcap connectors were implanted around the rat chorda tympani nerve. Whole nerve recordings under anesthesia were made from these nerves every week to chemical, thermal and tactile stimuli applied to the anterior tongue. The signal/noise ratio of these recordings was similar to acute recordings from the chorda tympani nerve, and the nerves were spontaneously active. Responses to chemical as well as thermal and mechanical stimulation of the tongue were recorded as early as 2 and 3 weeks after implantation and recordings from the same nerve were made for more than 3 months. These results have demonstrated the feasibility of making long-term chronic recordings of chemosensory activity in the chorda tympani nerve. The cuff electrode has great potential to provide correlative information between neurophysiological and behavioral data. (C) 2002 Elsevier Science Inc. All rights reserved.
\end{abstract}

Keywords: Taste; Chorda tympani nerve; Chronic recording; Rat

\section{Introduction}

Pioneering investigators studying the neurophysiology of the peripheral gustatory system recorded responses from the chorda tympani nerve to stimulation of the tongue with chemical solutions $[1,17,26]$. In these and many later studies, the chorda tympani branch of the facial nerve (cranial nerve VII), which innervates taste buds on the anterior tongue, is exposed, cut centrally and then prepared for conventional whole nerve or single fiber neurophysiological recording. Thus, almost all peripheral nerve recordings have been acute short-term experiments on decentralized nerves. In addition, because of the extensive surgical approach generally used to expose the chorda tympani, it is not possible to make long-term chronic recordings from the chorda tympani in awake animals for correlative studies of afferent neural activity and behavior.

To overcome these problems, a neural implant has been developed that consists of a cuff electrode positioned around the chorda tympani nerve that is connected to a percutan-

* Corresponding author. Department of Biologic and Materials Sciences, School of Dentistry, University of Michigan, Room 6228, Ann Arbor, MI 48109-1078, USA. Tel.: +1-734-763-1080; fax: +1-734-6472110.

E-mail address: rmbrad@umich.edu (R.M. Bradley). eous headcap. We now present the results of these experiments, demonstrating that it is possible to make long-term chronic recordings from taste fibers of the chorda tympani nerve in rats.

\section{Methods}

\subsection{Cuff electrode fabrication}

Cuff electrodes were fabricated from a flexible, silicon polymer in which the recording electrode was embedded. The electrodes were made by injecting the polymer (KwickSil, World Precision Instruments) into a mold made of a small diameter Teflon tube. Then, a fine wire mandrel, similar in diameter to the chorda tympani nerve, was positioned in the polymer to create a lumen in the cuff. After the polymer set, the mandrel was removed and a single platinum-iridium wire (A-M systems, Teflon-coated platinum-iridium wire, 0.0014 in. diameter), insulated except at the cuff end, was pushed into the cuff and fixed with additional polymer material. The cuff electrode was then removed from the Teflon tube that had been used as a mold. A second indifferent electrode, together with the electrode wire, was reinforced with a length of small diameter, Silastic tubing, cemented at both the cuff electrode and headcap ends. Finally, a slot was 
cut longitudinally in the cuff to permit placement of the nerve into the cuff lumen.

The headcap consisted of a machined titanium housing with a base flange, containing holes to fasten the housing to the skull with titanium screws [3]. Inserted into the housing was a Teflon connector with four embedded gold pins that go all the way to the bottom of the Teflon insert. The electrode and indifferent electrode wires were soldered to the base of two gold pins. An additional pin was connected to the titanium housing and served as a ground connection. Similar cuff electrodes have been described by others and describe the fabrication process in some detail $[7,8,21]$.

\subsection{Surgery}

Female Sprague-Dawley rats weighing $200 \mathrm{~g}$ were anesthetized with an intraperitoneal injection of sodium pentobarbital (50 mg/kg body weight) and laid supine on a heating pad. A midline incision was made in the skin overlying the anterior belly of the digastric muscle, which was separated from the masseter muscle by blunt dissection. The lingual nerve was exposed and followed until the chorda tympani nerve separates from it.

A second incision was made through the skin on the skull and via blunt dissection. Using a fine hemostatic forcep, a tunnel was made along the skull inside of the zygomatic arch towards the exposed chorda tympani nerve. The implant was passed through the tunnel and the headcap secured with titanium screws (W. Lorenz, $1 \mathrm{~mm}$ diameter, $4 \mathrm{~mm}$ long). The chorda tympani nerve was carefully freed from surrounding connective tissue and placed through the slot into the lumen of the cuff electrode. The nerve was secured in the cuff by application of additional silicon compound, which fills the slot in the cuff.

All incisions were closed using 5-0 suture and a recording was made from the cuff to tongue application of 1-M $\mathrm{NaCl}$ and tactile stimulation. The ability to record responses to these two stimuli was generally indicative of a successful implant. Rats were given a postsurgical regimen of antibiotics and carefully monitored until they began to feed. The rats were housed individually on ad lib food and water and were checked daily for any signs of postsurgical discomforts or stress. Surgical procedures were carried out under National Institutes of Health and the University of Michigan Animal Care and Use Committee approved protocols.

\subsection{Electrophysiological recordings}

After the cuff electrode had been in place for 2 weeks to permit complete healing, electrophysiological recordings were made every week. The rats were anesthetized with a short-acting anesthetic consisting of an intramuscular injection of a 1:1 mixture of Rompun ( $2 \mathrm{mg} / \mathrm{kg}$ body weight $)$ and ketamine $(10 \mathrm{mg} / \mathrm{kg}$ body weight). This provided about $1 / 2 \mathrm{~h}$ of surgical level anesthesia for recording. During all testing, the rat's cornea was protected from desiccation by applying a protective ointment.

Once the animal was anesthetized, the external amplifying equipment was connected to the headcap plug. The anesthetized animal was laid on its side and the tongue retracted to expose the fungiform papillae and associated taste buds. The chorda tympani nerve responds to mechanical, thermal and chemical stimulation of the tongue $[18,25]$ and all of these stimulus modalities were used in our experiments. Mechanical and thermal stimuli consisted of stroking the tongue with a blunt rod and applying $2{ }^{\circ} \mathrm{C}$ water, respectively. Chemical stimuli, at room temperature, applied at $0.5 \mathrm{ml} / \mathrm{s}$ through a gravity flow system to the exposed tongue tip, were a concentration series of $0.01-1.0-\mathrm{M} \mathrm{NaCl}, 1-\mathrm{M} \mathrm{NH} \mathrm{N}_{4} \mathrm{Cl}$, $0.01-\mathrm{M} \mathrm{HCl}, 1.0-\mathrm{M}$ citric acid, $0.1-\mathrm{M} \mathrm{QuHCl}$ and 1.0-M

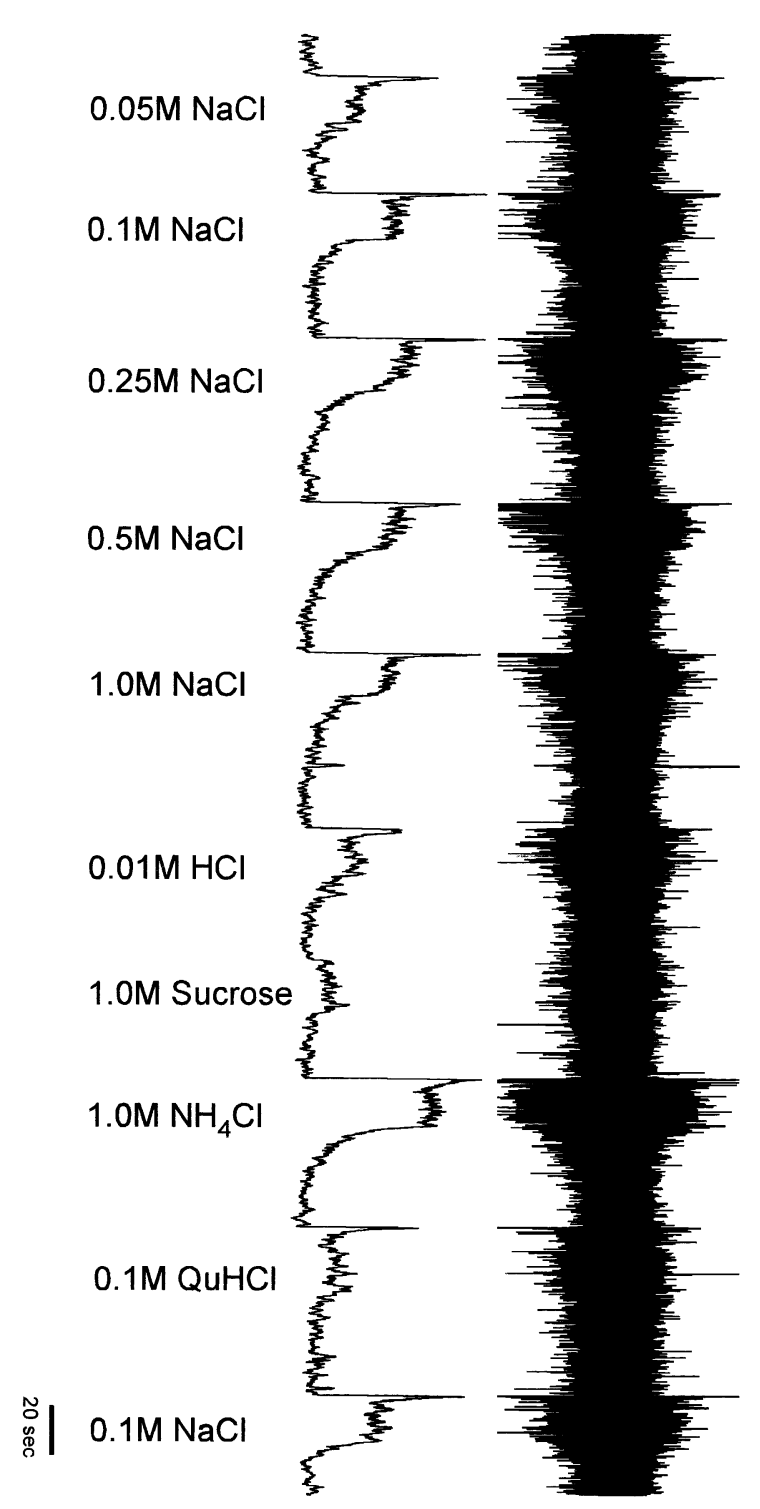

Fig. 1. Recording from a chorda tympani nerve 5 weeks after implantation. The upper record is of the amplified neural discharges and the lower record is the integrated responses. 


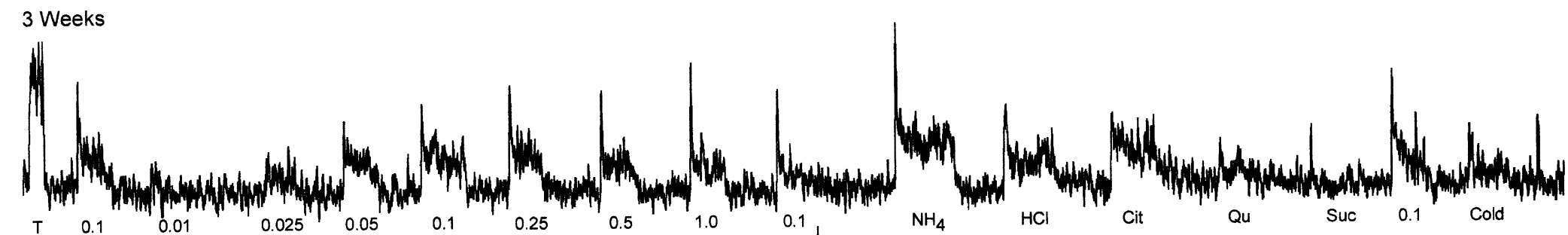
4 Weeks

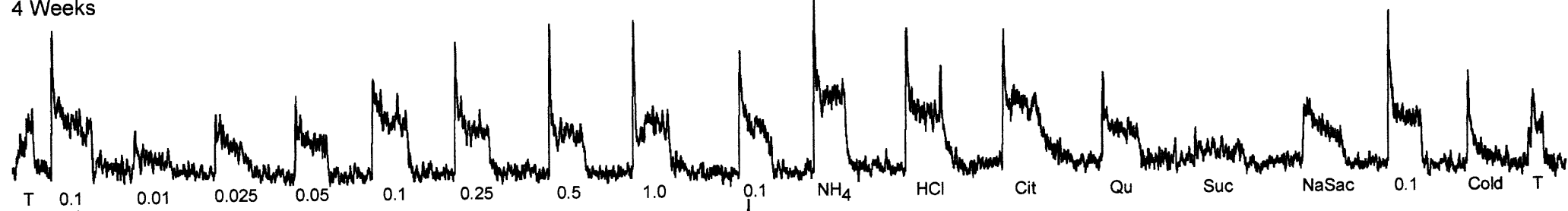
5 Week
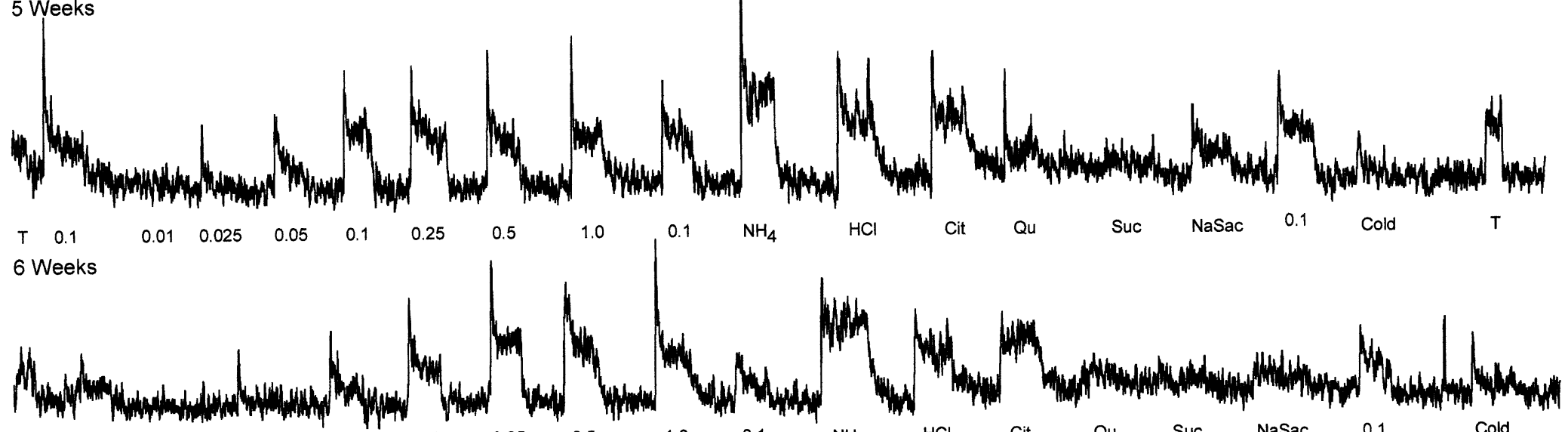

6 Weeks

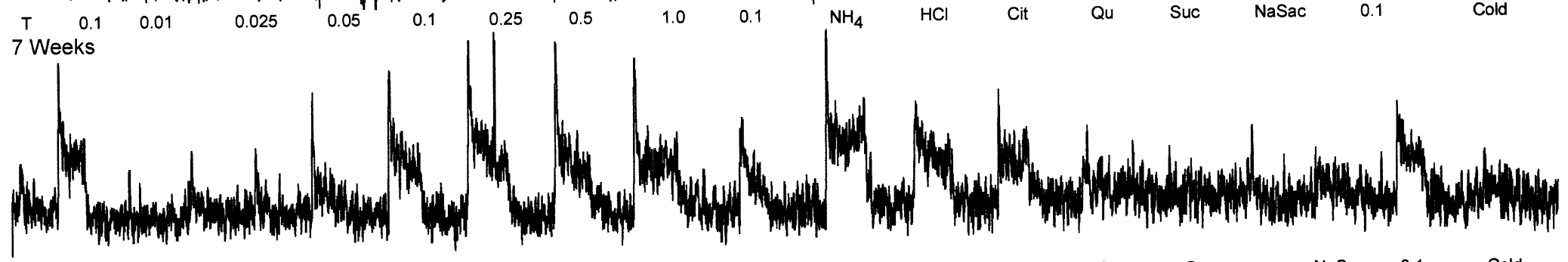


sucrose, freshly diluted prior to each experiment. All solutions were made in distilled water and applied at room temperature. Stimuli were flowed over the tongue for $\sim 20 \mathrm{~s}$ and the tongue was then rinsed continually for $30 \mathrm{~s}$ before the next stimulus was applied. $\mathrm{NaCl}(0.1 \mathrm{M})$ was applied several times to monitor the stability of the recordings and control for any long-lasting effect that stimuli may have on the receptors.

\subsection{Data analysis}

The recording equipment consisted of a high gain $\mathrm{AC}$ amplifier (Grass P511), an oscilloscope and an audio amplifier. In addition, the amplified signals were connected to an A/D converter (Cambridge Electronic Design 1401 Plus) interfaced to a computer. Data were acquired by the software program Spike 2 (Cambridge Electronic Design). To facilitate analysis of the whole nerve data, it was first rectified and then filtered to create a running average of the responses [1]. In the past, this form of data reduction, to create what has been termed an integrated response, was achieved electronically. We accomplished this analysis with a software routine written in the script language that comes with the Spike 2 software. The data were stored on the hard drive of the computer. Gain and bandwidth of the amplifier remained the same for all of the recording sessions.

After termination of the experiment, the whole nerve and integrated data were printed. For each stimulus, the average height of the steady-state portion of the integrated response during the 5-10th $\mathrm{s}$ above baseline was measured as response units $(\mathrm{mm})$. To compare the integrated response magnitude among different stimuli, and from week to week in the same animal, relative response ratios were calculated. For each experiment, the response of a particular stimulus was calculated relative to the response to $0.1-\mathrm{M} \mathrm{NaCl}$. The response-concentration curve for $\mathrm{NaCl}$ was fitted using the Boltzman equation.

\section{Results}

Chronic long-term recordings from the same chorda tympani nerve were successfully accomplished in nine animals. Examination of the whole nerve neural recordings from the cuff electrode (Fig. 1) reveals that nerves were spontaneously active and the signal/noise ratio was comparable to published recordings from cut decentralized nerves $[6,10]$. Responses to chemical as well as thermal and mechanical stimulation of the tongue were recorded as early as 2 and 3 weeks after implantation. An example of the responses recorded for Weeks 3-7 to mechanical, thermal and chemical stimulation of the tongue is shown in Fig. 2. This figure illustrates robust responses to mechanical and thermal stimulation at 3 weeks after implantation and responses to a concentration series of $\mathrm{NaCl}$ and other chemical stimuli.

Recordings were made on a weekly basis for periods ranging from 3 to 16 weeks. Fig. 3 shows recordings of the integrated data from an animal at 12 and 14 weeks after implantation, illustrating that the quality of the data recorded from the same nerve is maintained for over 3 months.
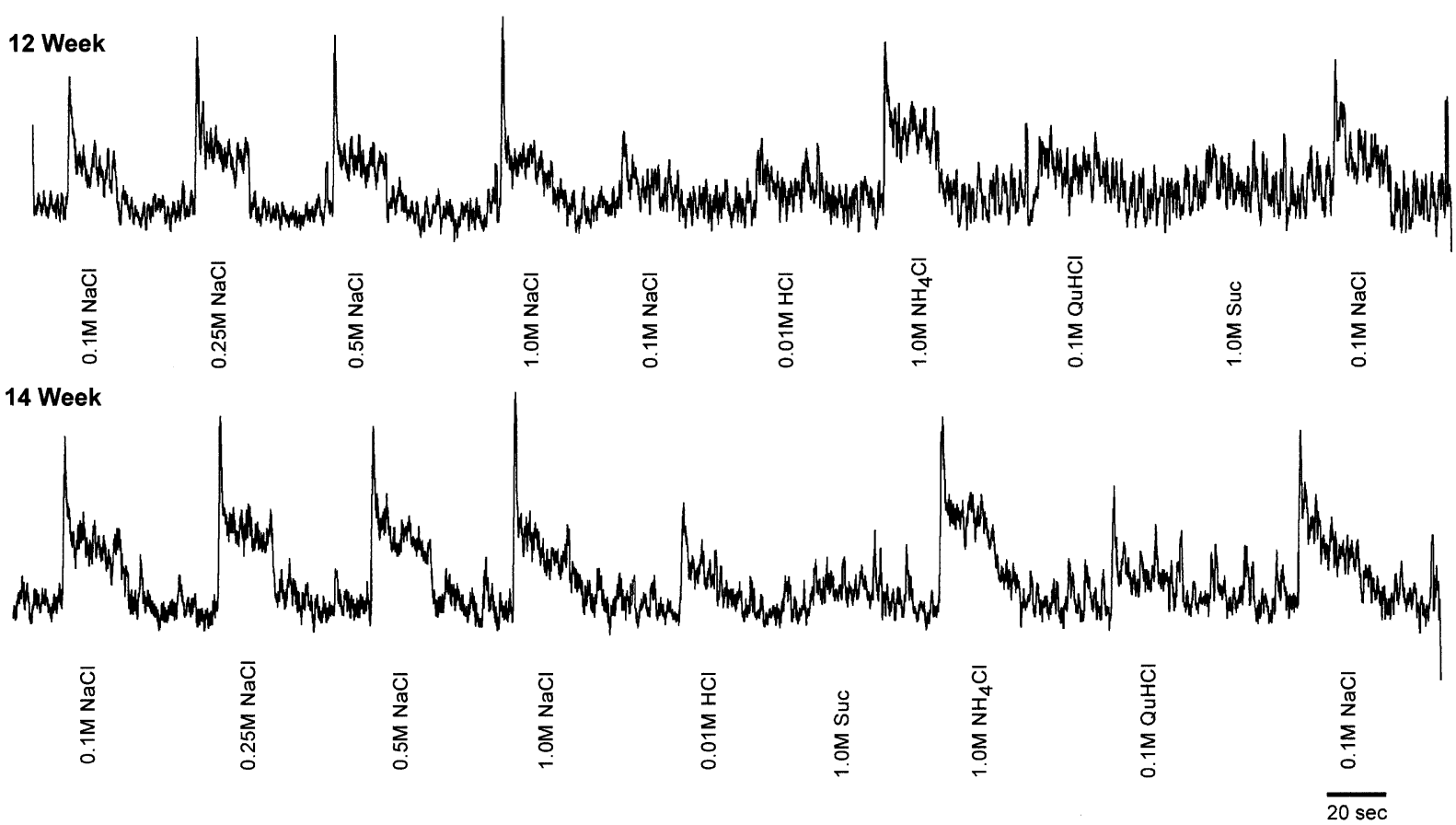

Fig. 3. Integrated records of responses of a chorda tympani nerve at 12 and 14 weeks after implantation, illustrating the possibility of recording robust taste responses from the same chorda tympani nerve for long time periods. 
Experiments were terminated either due to mechanical failure (usually after the headcap was lost or became loose) or because the signal/noise ratio deteriorated. In a study of the cat sciatic nerve implanted with a cuff electrode, Loeb and Peck [9] report that the eventual decline in response results from proliferation of connective tissue into the cuff. However, it was possible to make chronic high-quality, whole nerve recordings from the same chorda tympani nerve for up to 16 weeks.

\subsection{Responses to a $\mathrm{NaCl}$ concentration series}

Responses to a concentration series of salts have been well documented in the cut chorda tympani nerve $[1,11]$. Therefore, response-concentration functions provide a valuable indicator of the integrity of taste nerve responses. An example of the chronic responses to an increasing concentration of $\mathrm{NaCl}$ is presented in Fig. 4. Data plotted in Fig. 4A are the integrated response units measured weekly from 3 to 7 weeks

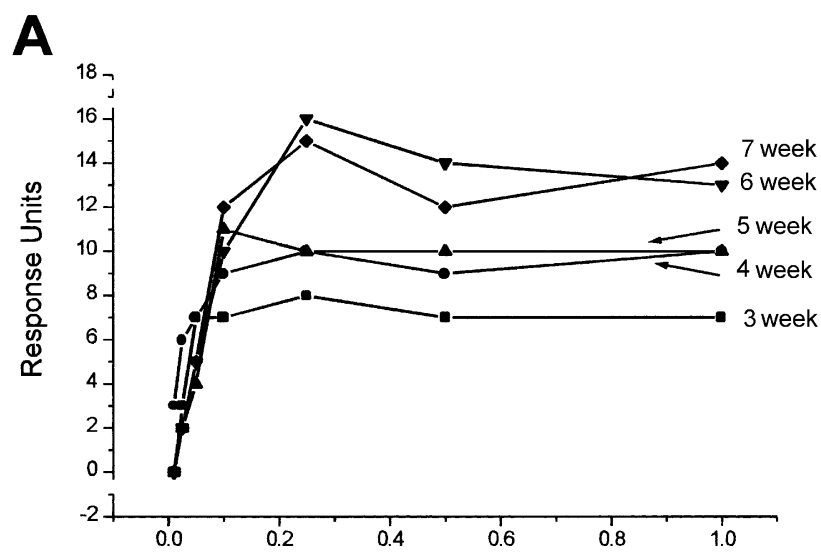

B

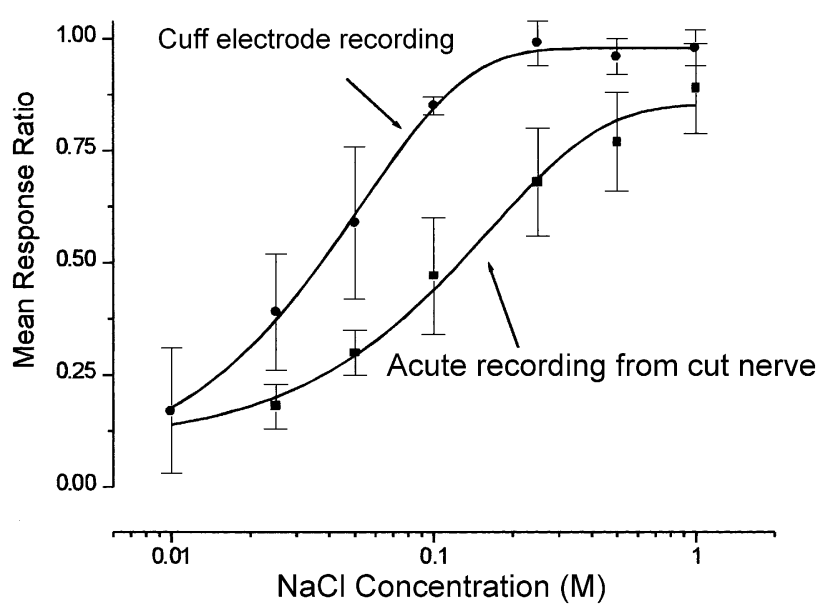

Fig. 4. (A) Response-concentration functions recorded weekly from one animal. (B) Mean and standard errors of the data derived from (A). When compared to concentration functions derived from recordings in an acute preparation in which the nerve is cut, the response-concentration curve from the cuff electrode recordings is shifted to the left. The curves were fitted using the Boltzman equation.
A

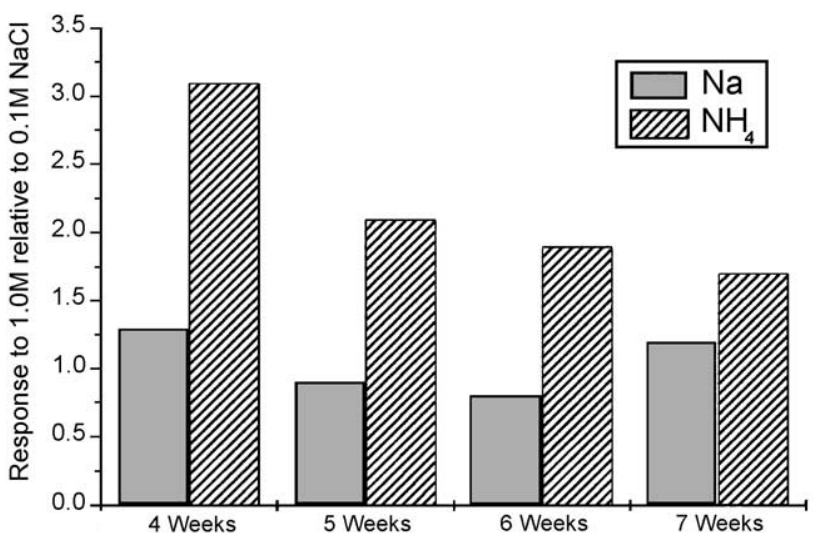

B

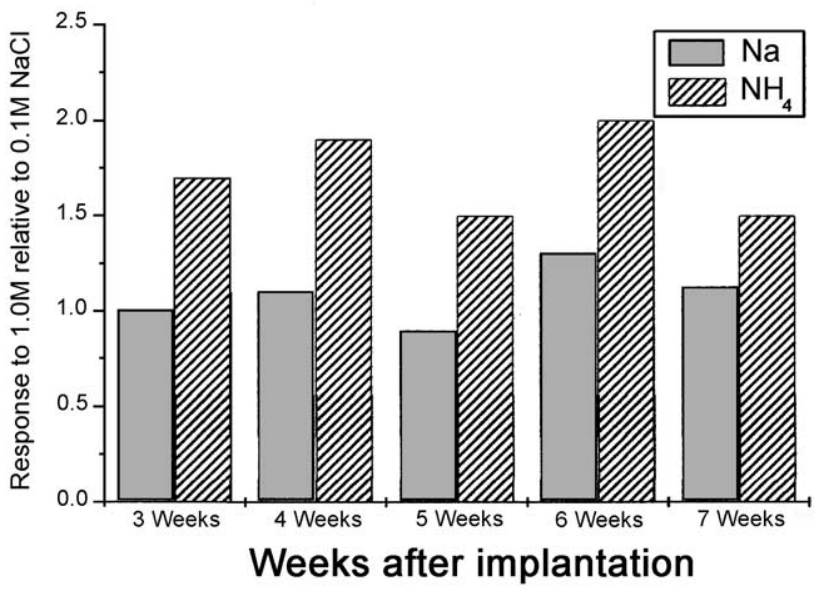

Fig. 5. Ratios of responses to $1.0-\mathrm{M} \mathrm{NaCl}$ and $1.0-\mathrm{M} \mathrm{NH}_{4} \mathrm{Cl}$ relative to the response to $0.1-\mathrm{M} \mathrm{NaCl}$ for two animals ( $\mathrm{A}$ and $\mathrm{B}$ ) recorded weekly.

after implantation. These same data are plotted as mean values for all weeks in Fig. 4B and demonstrate that the chronic chorda tympani nerve recordings have a similar dynamic response range as that reported in the literature. However, the shape of the response-concentration curve in the chronic recordings differs from the curve in the acute recordings in which the nerve is cut (Fig. 4B). The concentration function generated from the cuff electrode recordings saturates at $0.25 \mathrm{M}$, whereas the curve for the acute recordings saturates between 0.5 and $1.0 \mathrm{M}$ of $\mathrm{NaCl}$. The data used to generate the acute response-concentration curves were derived from unpublished experiments conducted some time ago.

\subsection{Relative responses to the four basic taste qualities}

Calculations of the ratio of the integrated response magnitude to $1.0-\mathrm{M} \mathrm{NaCl}$ and $1.0-\mathrm{M} \mathrm{NH} \mathrm{NH}_{4} \mathrm{Cl}$, relative to the response magnitude to $0.1-\mathrm{M} \mathrm{NaCl}$, are presented in Fig. 5 . For all the animals, the response to $\mathrm{NH}_{4} \mathrm{Cl}$ was always larger than the response to $\mathrm{NaCl}$ (see also Fig. 1). Examples of these response ratios recorded weekly in two animals are 


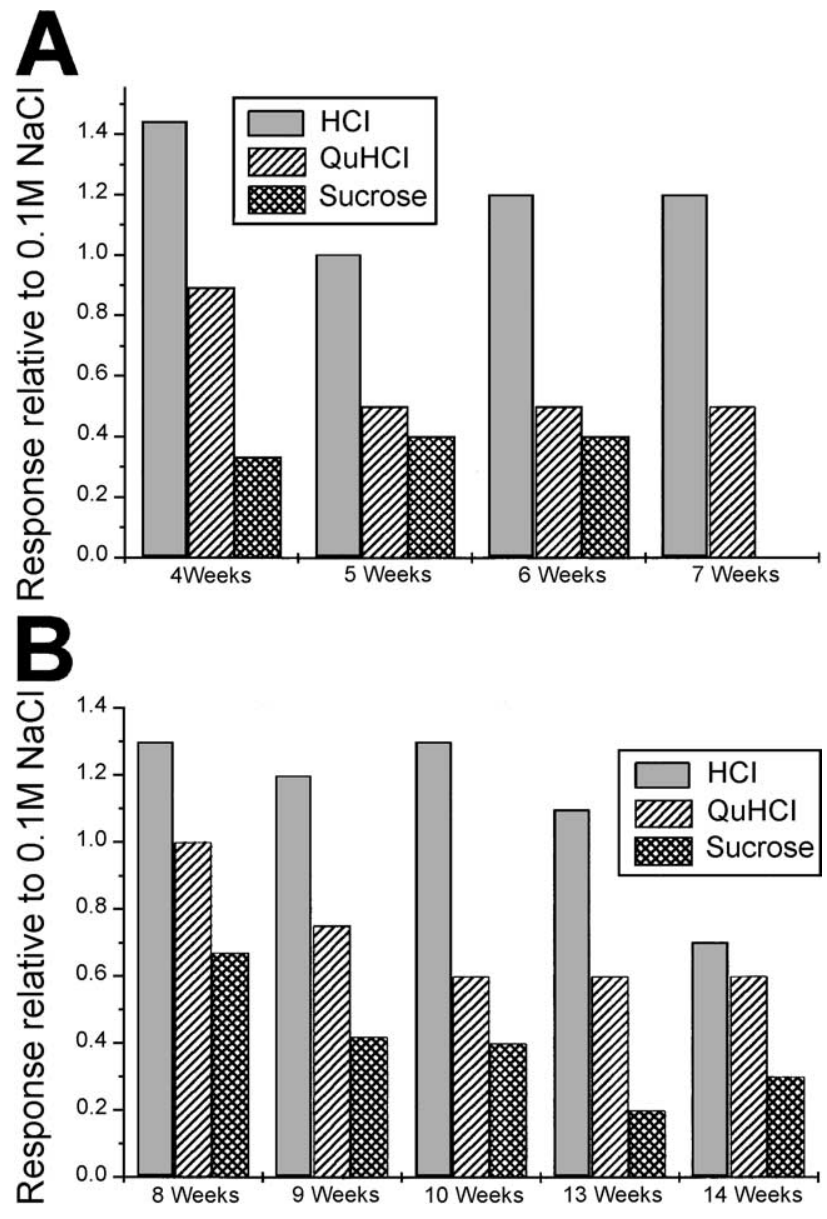

Fig. 6. Ratios of responses to $\mathrm{HCl}, \mathrm{QuHCl}$ and sucrose relative to the response to $0.1-\mathrm{M} \mathrm{NaCl}$ for two animals (A and $\mathrm{B}$ ) recorded weekly.

shown in Fig. $5 \mathrm{~A}$ and $\mathrm{B}$, with a response to $1.0-\mathrm{M} \mathrm{NH} \mathrm{NH}_{4} \mathrm{Cl}$ persistently greater than the response to $1.0-\mathrm{M} \mathrm{NaCl}$. In Fig. $6 \mathrm{~A}$ and $\mathrm{B}$, the response ratios of the chorda tympani nerve to $0.01-\mathrm{M} \mathrm{HCl}, 0.1-\mathrm{M}$ quinine $\mathrm{HCl}$ and 1-M sucrose, relative to $0.1-\mathrm{M} \mathrm{NaCl}$, are plotted on a weekly basis (see also Fig. 1). In these two animals, the order of response magnitude is $\mathrm{HCl}>\mathrm{QuHCl}>$ sucrose.

\section{Discussion}

To our knowledge, these are the first long-term chronic recordings from the uncut chorda tympani nerve. The responses have an excellent signal/noise ratio and are very stable, permitting repeated analysis of mechanical, thermal and chemical responses from the same animal over time. The only other recordings from the gustatory system of the same animal over time are extracellular recordings from neurons in the central nervous system in rats and monkeys $[12-16,20,22,23]$. The goals of these experiments differ from those of the present study. In recordings from the ascending taste relay nuclei, the aim was not to record from the same neuron over time but to record from gustatory neurons in awake animals to eliminate the effect of anesthesia on CNS neurons and permit recordings to be made in behaving animals.

Although the chorda tympani nerve is not cut in the cuff electrode experiments, and taste evoked recordings could be made from the chorda tympani at the time of implantation, the nerve then became insensitive. After a minimum of 2 weeks of postimplantation, the nerve regained its sensitivity. Apparently, therefore, the nerve degenerated and then regenerated. The time course of the return of responsiveness suggests that the surgery to place the cuff electrode was similar to performing a nerve crush. Other investigators have crushed the chorda tympani and glossopharyngeal nerves in rats [4,24], gerbils [5] and cats [19] to evaluate the recovery of the peripheral taste system. After nerve crush, although the number of myelinated fibers in the chorda tympani is decreased, the number of taste buds approached control numbers. Moreover, by 4 weeks, responses to taste stimuli were similar to recordings made in control animals [4]. Thus, the recordings made using a cuff electrode are probably similar to acute short-term recordings made immediately after the nerve is cut.

The ability to make chronic recordings from a peripheral nerve has been the goal of numerous investigators. The cuff electrode is a relatively simple approach to achieve this goal, and as we have demonstrated, it is capable of recording from afferent nerve fibers for a long time. As a research tool, it has, therefore, great potential for providing information on afferent nerve activity and, when the recordings are performed in unanesthetized behaving animals, will provide correlations between behavior and neural activity. Cuff electrode recordings will also be extremely useful to examine the influence of various interventions on taste responses, eliminating the need to compare control and experimental animals. For example, it will be possible to directly determine the effect of a mitogen or drug treatment on taste responses in the same animal.

However, to examine other changes in taste response over time would require recordings from single fibers. For example, to examine the pattern of neural activity during the life cycle of a taste cell [2] single fiber recordings is necessary because recordings from the whole nerve represent an average of all the fiber activity.

In conclusion, we have demonstrated the feasibility of making long-term chronic recordings of chemosensory activity in the rat chorda tympani nerve. The cuff electrode has great potential when combined with other experimental procedures for answering new questions about mechanisms of taste coding and the stability of the taste responses over time.

\section{Acknowledgments}

This work was supported by National Institutes of Health Grant DC00059 to R.M.B. 


\section{References}

[1] Beidler LM. Properties of chemoreceptors of tongue of rat. J Neurophysiol 1953;16:595-607.

[2] Beidler LM, Smallman RL. Renewal of cells within taste buds. J Cell Biol 1965;27:263-72.

[3] Bradley RM, Cao X, Akin T, Najafi K. Long term chronic recording from peripheral sensory fibers using a sieve electrode array. J Neurosci Methods 1997;73:177-86.

[4] Cain P, Frank ME, Barry MA. Recovery of chorda tympani nerve function following injury. Exp Neurol 1996;141:337-46.

[5] Cheal M, Dickey WP, Jones LB, Oakley B. Taste fiber responses during reinnervation of fungiform papillae. J Comp Neurol 1977; 172:627-46.

[6] Cohen MJ, Hagiwara S, Zotterman Y. The response spectrum of taste fibres in the cat: a single fibre analysis. Acta Physiol Scand 1955;33: $316-32$.

[7] Jellema T, Teepen JLJM. A minaturized cuff electrode for electrical stimulation of peripheral nerves in the freely moving rat. Brain Res Bull 1995;37:551-4.

[8] Julien C, Rossignol S. Electroneurographic recordings with a polymer cuff electrodes in paralyzed cats. J Neurosci Methods 1982;5: 267-72.

[9] Loeb GE, Peck RA. Cuff electrodes for chronic stimulation and recording of peripheral nerve activity. J Neurosci Methods 1996;64: $95-103$

[10] Matsuo R, Yamamoto T, Ikehara A, Nakamura O. Effect of salivation on neural taste responses in freely moving rats: analyses of salivary secretion and taste responses of the chorda tympani nerve. Brain Res 1994;649:136-46.

[11] McBride MR, Mistretta CM. Taste responses from the chorda tympani nerve in young and old Fischer rats. J Gerontol 1986;41:306-14.

[12] Nakamura K, Norgren R. Gustatory responses of neurons in the nucleus of the solitary tract of behaving rats. J Neurophysiol 1991;66: $1232-48$.

[13] Nakamura K, Norgren R. Taste responses of neurons in the nucleus of the solitary tract of awake rats: an extended stimulus array. J Neurophysiol 1993;70:879-91.

[14] Nishijo H, Ono T, Norgren R. Parabrachial gustatory neural responses to monosodium glutamate ingested by awake rats. Physiol Behav 1991;49:965-71.

[15] Nishijo H, Norgren R. Parabrachial gustatory neural activity during licking by rats. J Neurophysiol 1991;66:974-84.

[16] Nishijo H, Norgren R. Parabrachial neural coding of taste stimuli in awake rats. J Neurophysiol 1997;78:2254-68.

[17] Pfaffmann C. Gustatory afferent impulses. J Cell Comp Physiol 1941; $17: 243-58$

[18] Robinson PP. The characteristics and regional distribution of afferent fibres in the chorda tympani of the cat. J Physiol 1988;406:345-59.

[19] Robinson PP, Winkles PA. The number and distribution of fungiform papillae and taste buds after lingual nerve injuries in cats. Arch Oral Biol 1991;36:885-91.

[20] Rolls ET, Yaxley S, Sienkiewicz ZJ. Gustatory responses of single neurons in the caudolateral orbitofrontal cortex of the macaque monkey. J Neurophysiol 1990;64:1055-65.

[21] Sauter JF, Berthoud HR, Jeanrenaud B. A simple electrode for intact nerve stimulation and/or recording in semi-chronic rats. Pfluegers Arch 1983;397:68-9.

[22] Scott TR, Yaxley S, Sienkiewicz ZJ, Rolls ET. Gustatory responses in the nucleus tractus solitarius of the alert cynomolgus monkey. J Neurophysiol 1986;55:182-200.

[23] Scott TR, Yaxley S, Sienkiewicz ZJ, Rolls ET. Gustatory responses in the frontal opercular cortex of the alert cynomolgus monkey. J Neurophysiol 1986;56:876-90.

[24] Smith DV, Klevitsky R, Akeson RA, Shipley MT. Expression of the neural cell adhesion molecule (NCAM) and polysialic acid during taste bud degeneration and regeneration. J Comp Neurol 1994;347: 187-96.

[25] Yamashita S, Ogawa H, Sato M. Multimodal sensitivity of taste units in the rat. Kumamoto Med J 1967;20:67-70.

[26] Zotterman Y. Action potentials in the glossopharyngeal nerve and in the chorda tympani. Skand Arch Physiol 1935;72:73-5. 